\title{
Clinical Experience with Kurjak Antenatal Neurodevelopmental Test in Low- and High-risk Pregnancies
}

\author{
${ }^{1}$ Octavian Rotaru, ${ }^{2}$ Radu Vladareanu, ${ }^{3}$ Anca Burnei, ${ }^{4}$ Carmen Cristea, ${ }^{5}$ Simona Vladareanu
}

\section{ABSTRACT}

Introduction: To assess whether there is a difference in the behavior of fetuses from high-risk pregnancies compared with fetuses from low-risk pregnancies.

Materials and methods: We applied the Kurjak antenatal neurodevelopmental test (KANET) in high-risk $(n=65)$ and lowrisk $(n=119)$ pregnancies and compared the results. High-risk pregnancies included women with threatened preterm delivery (with premature rupture of membranes and without premature rupture of membranes), hypertension, diabetes, intrauterine growth restriction, and $\mathrm{Rh}$ isoimmunization.

Results: There was a difference between the results of KANET applied in these two groups; most of borderline and abnormal results were found in high-risk group, especially from pregnancies complicated by threatened preterm labor. The subgroup of pregnant women with premature rupture of membranes had most of the modified KANET scores.

Conclusion: The median values of the movements of fetuses in low-risk pregnancies were different from those in pregnancies threatened by premature birth and from the rest of the high-risk pregnancies. Fetuses from high-risk pregnancies, including threat of premature birth, had a less active fetal behavior than those from low-risk group.

Keywords: Fetal behavior, High-risk pregnancies, Kurjak antenatal neurodevelopmental test.

How to cite this article: Rotaru O, Vladareanu R, Burnei A, Cristea C, Vladareanu S. Clinical Experience with Kurjak Antenatal Neurodevelopmental Test in Low- and High-risk Pregnancies. Donald School J Ultrasound Obstet Gynecol 2018;12(1):17-22.

\section{Source of support: Nil}

Conflict of interest: None

\footnotetext{
${ }^{1,4}$ Researcher, ${ }^{2}$ Professor and Chairman, ${ }^{3}$ Lecturer, ${ }^{5}$ Professor

${ }^{1-4}$ Department of Obstetrics and Gynecology, Carol Davila University of Medicine and Pharmacy, Elias Emergency University Hospital, Bucharest, Romania

${ }^{5}$ Department of Obstetrics and Gynecology and Neonatology Carol Davila University of Medicine and Pharmacy, Elias Emergency University Hospital, Bucharest, Romania

Octavian Rotaru and Radu Vladareanu contributed equally

Corresponding Author: Radu Vladareanu, Professor and Chairman, Department of Obstetrics and Gynecology Carol Davila University of Medicine and Pharmacy, Elias Emergency University Hospital, Bucharest, Romania, Phone: +40722351081, e-mail: vladareanu@gmail.com
}

\section{INTRODUCTION}

It is known that obstetricians and neonatologists had some hard time over the years studying the fetal nervous system. The major task is the detection and prevention of early neurological damage..$^{1-3}$

In order to better understand the fetal neurological function, the obstetrician needs to better define the normal and abnormal fetal neurological function in utero to predict which fetuses are at risk for adverse neurological outcomes. ${ }^{4,5}$ Many factors, such as genetic, external, or pathological conditions can affect the fetal human brain up to a degree that is difficult to assess prenatally. Cerebral palsy is one of the many functional neurological abnormalities that is poorly understood and needs further investigation. ${ }^{6}$ Further advancement was the introduction of high-quality three-dimensional/four-dimensional ultrasound (3D/4D US), which allowed the observation of dynamic fetal activity with good image resolution. ${ }^{7}$ Therefore, it was assumed that the 4D US evaluation of fetal behavior can give the possibility to differentiate the normal from abnormal brain development. The ability of $4 \mathrm{D}$ sonography to visualize the fetal face and its movements and study the facial expressions, including grimace, tongue expulsion, isolated eye blinking, mouth movements, yawning, which 2D US does not, achieved the real breakthrough. ${ }^{8,9}$

This new technology made possible the introduction of KANET (Kurjak antenatal neurodevelopmental test) in low- and high-risk pregnancies, distinguishing between normal and abnormal brain development. ${ }^{10}$

The aim of this study was to apply the new antenatal scoring system KANET to fetuses from high-risk pregnancies for neurological disorders and to compare it with fetuses from low-risk pregnancies.

\section{MATERIALS AND METHODS}

During a period of almost 12 months, between June 2016 and May 2017, KANET was applied in 184 singleton pregnancies between 28 and 36 weeks of gestation, recruited in the Department of Obstetrics and Gynecology, Elias University Emergency Hospital, Bucharest, Romania. The inclusion criteria were singleton pregnancies considered "normal" after 2D US examination and pregnancies with high maternal and fetal risk, listed in Table 1. The exclusion criteria are prenatally diagnosed fetal chromosomal 
Table 1: Inclusion criteria

\begin{tabular}{ll}
\hline Maternal disorders & Hypertension, type II diabetes mellitus \\
Fetal disorders & Intrauterine growth restriction \\
Pathological conditions & Gestational diabetes, Rh incompatibility, \\
related to the pregnancy & threatened preterm delivery \\
\hline
\end{tabular}

abnormalities and maternal cigarette and/or alcohol consumption during the pregnancy.

Fetal behavior was assessed by 4DUS. All the examinations were performed using Voluson E8, with volumetric transabdominal $7 \mathrm{MHz}$ transducer, by doctors trained in KANET, who were informed about the risk of the pregnancy.

Each patient gave her informed consent to the study.

For assessment of fetal neurobehavior, we used the KANET scoring system presented in Table $2{ }^{7}$

Table 3 represents the interpretation of the KANET scores, classifying fetuses into three groups after KANET assessment: normal 14 to 20 points, borderline 6 to 13 points, and abnormal 0 to 5 points. The KANET was repeated every 2 weeks until delivery for borderline and abnormal scores.

The examination maximum time was 30 minutes, with fetus awake and mothers who had avoided food, coffee, and tea for 2 hours before the examination.

Each parameter of KANET and its meaning is described elsewhere. ${ }^{11}$

The usefulness of KANET to identify fetuses from high-risk pregnancies at neurological risk was the primary outcome.

\section{RESULTS}

In this prospective cohort study of 184 singleton pregnancies between 28 and 36 weeks of gestation, 119 are low-risk pregnancies and 65 are high-risk pregnancies.

Table 2: The KANET

\begin{tabular}{|c|c|c|c|c|}
\hline \multirow[b]{2}{*}{ Sign } & \multicolumn{3}{|c|}{ Score } & \multirow{2}{*}{$\begin{array}{l}\text { Sign } \\
\text { Score }\end{array}$} \\
\hline & 0 & 1 & 2 & \\
\hline Isolated head anteflexion & Abrupt & $\begin{array}{l}\text { Small range } \\
\text { ( } 0-3 \text { times of } \\
\text { movements) }\end{array}$ & $\begin{array}{l}\text { Variable in full } \\
\text { range, many } \\
\text { alternation } \\
\text { (>3 times of } \\
\text { movements) }\end{array}$ & \\
\hline
\end{tabular}

8

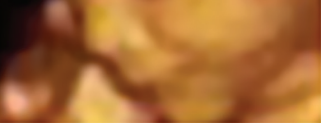

Cranial sutures and head circumference
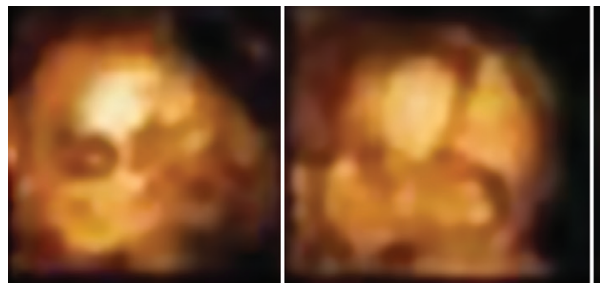

Isolated eye blinking

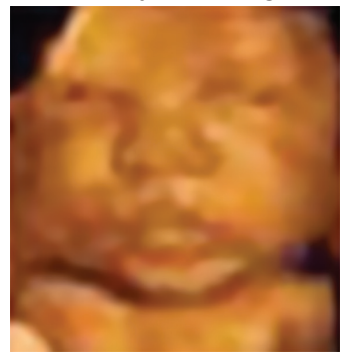

Facial alteration (grimace or tongue expulsion)



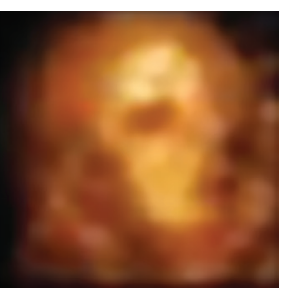

Overlapping

of cranial

sutures head

circumference

below or above

the normal

limit (-2SD)

according to

GA

Not present

Not fluent

(1-5 times of

blinking)
Normal cranial

sutures

normal head

circumference
Fluency

(> 5 times of blinking)

(Cont'd...)

\begin{tabular}{|c|c|c|}
\hline Not present & $\begin{array}{l}\text { Not fluent } \\
\text { (1-5 times of } \\
\text { alteration) }\end{array}$ & $\begin{array}{l}\text { Fluency } \\
\text { (>5 times of } \\
\text { alteration) }\end{array}$ \\
\hline
\end{tabular}




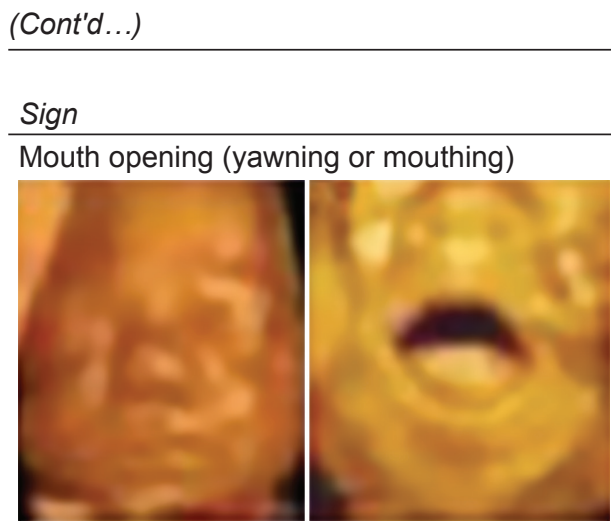

Isolated hand movement

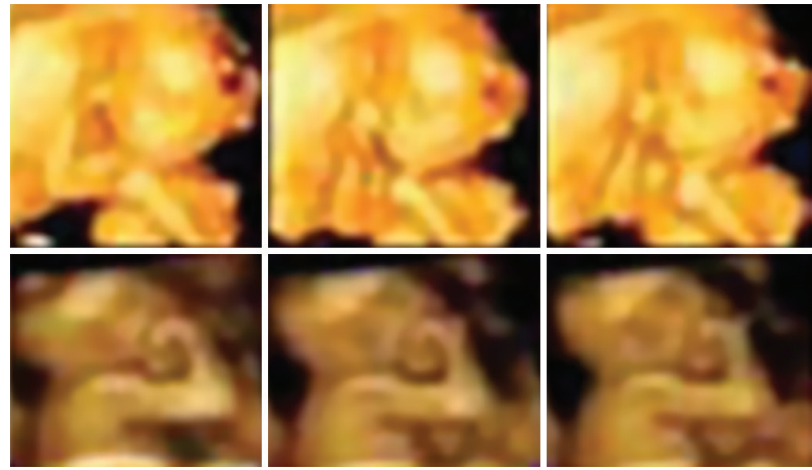

Isolated leg movement


Hand to face movements

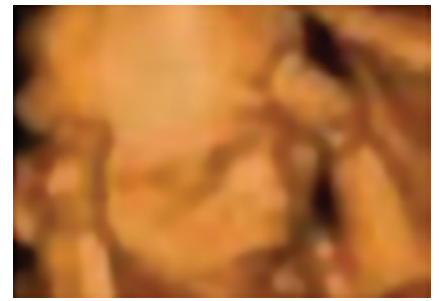

Fingers movements



Gestalt perception of GMs

\begin{tabular}{|c|c|c|c|}
\hline \multicolumn{3}{|c|}{ Score } & \multirow{2}{*}{$\begin{array}{l}\text { Sign } \\
\text { Score }\end{array}$} \\
\hline 0 & 1 & 2 & \\
\hline Not present & $\begin{array}{l}\text { Not fluent } \\
\text { (1-3 times of } \\
\text { alteration) }\end{array}$ & $\begin{array}{l}\text { Fluency } \\
\text { (>3 times of } \\
\text { alteration) }\end{array}$ & \\
\hline
\end{tabular}

Cramped

Cramped

Abrupt

Unilateralor bilateral clenched fist (neurological thumb)
Poor repertoire Variable and complex

Poor repertoire

Variable and complex

Variable in full range, many alternation (> 6 times of movement)

$\begin{array}{ll}\text { Cramped } & \text { Smooth and } \\ \text { invariable finger } & \text { complex, } \\ \text { movements } & \text { variable finger } \\ & \text { movements }\end{array}$

Cramped (0-5 times of movement) movements

Definitely $\quad$ Borderline
abnormal


Table 3: Interpretation of the total KANET score

\begin{tabular}{ll}
\hline Total score & Interpretation \\
\hline $0-5$ & Abnormal \\
$6-13$ & Borderline \\
$14-20$ & Normal \\
\hline
\end{tabular}

The final results showed one abnormal score and 5 borderline scores in the low-risk group, one of the five was a Prader-Willi syndrome (Table 4), diagnosed postnatally with methylation-specific multiplex ligationdependent probe amplification test. The KANET was performed every 2 weeks until delivery and found similar scores.

The Prader-Willi syndrome is a neurogenetic disorder, caused by chromosomal deletion on chromosome 15q11.2-q13, uniparental disomy for chromosome 15, or imprinting center defects affecting the gene expression in this region. It is characterized at the molecular level by abnormal methylation of imprinted regions at 15q11.2-q13 and it is associated in newborns with hypotonia, feeding problems, developmental delay, and/or mental retardation. ${ }^{11}$ In this particular case, the prenatal US findings did not reveal any abnormalities, and the KANET score was the sole parameter that was modified.

The high-risk group was divided into two subgroups: 39 pregnant women with threatened preterm delivery (with or without preterm premature rupture of membrane) and 26 pregnant women with other high-risk
Table 4: Clinical case: Prader-Willi syndrome

\begin{tabular}{ll}
\hline KANET: score 6-borderline & 2 \\
\hline Isolated head anteflexion & 0 \\
Cranial sutures and head circumference & 1 \\
Isolated eye blinking & 1 \\
Facial alterations & 1 \\
Mouth opening (yawning or mouthing) & 1 \\
Isolated hand movements & 0 \\
Leg movements & 0 \\
Hand-to-face movements & 0 \\
Fingers movements & 0 \\
Gestalt perception of general movements & 6 \\
\hline Total
\end{tabular}

conditions: hypertension, diabetes, intrauterine growth restriction, and $\mathrm{Rh}$ incompatibility. If premature rupture of membranes occurred in a patient included in another subgroup of high-risk pregnancies, she was still evaluated as belonging to the initial subgroup.

The results of $\mathrm{p}$-value of chi-square test for each parameter are shown in Table 5. Highly significant p-values are observed for isolated blinking, facial alterations, isolated hand movements, hand-to-face movements, and finger movements; meanwhile, significant $p$-values are noted for cranial sutures and mouth opening. Statistical analysis showed a significant $p$-value for cranial sutures and head circumference for the group of threatened preterm delivery, considering that there were two cases with preterm premature rupture of membranes

Table 5: Application of KANET in low-risk and high-risk pregnancies

\begin{tabular}{|c|c|c|c|c|c|}
\hline \multirow[b]{2}{*}{ Sign } & \multirow[b]{2}{*}{ Risk } & \multicolumn{3}{|c|}{ KANET score } & \multirow[b]{2}{*}{$p$-value } \\
\hline & & 0 & 1 & 2 & \\
\hline \multirow[t]{2}{*}{ Head anteflexion } & High & 1 & 16 & 48 & 0.081 \\
\hline & Low & 9 & 23 & 87 & \\
\hline \multirow[t]{2}{*}{ Cranial sutures } & High & 2 & 16 & 47 & 0.036 \\
\hline & Low & 10 & 30 & 79 & \\
\hline \multirow[t]{2}{*}{ Isolated blinking } & High & 9 & 25 & 31 & 0.000006 \\
\hline & Low & 7 & 27 & 85 & \\
\hline \multirow[t]{2}{*}{ Facial alterations } & High & 10 & 44 & 11 & $1.42 \times 10^{-11}$ \\
\hline & Low & 10 & 23 & 86 & \\
\hline \multirow[t]{2}{*}{ Mouth opening } & High & 6 & 32 & 27 & 0.00198 \\
\hline & Low & 5 & 28 & 86 & \\
\hline \multirow[t]{2}{*}{ Isolated hand movements } & High & 4 & 32 & 29 & 0.000091 \\
\hline & Low & 5 & 24 & 90 & \\
\hline \multirow[t]{2}{*}{ Isolated leg movements } & High & 0 & 17 & 48 & 0.265 \\
\hline & Low & 6 & 20 & 93 & \\
\hline \multirow[t]{2}{*}{ Hand-to-face movements } & High & 13 & 34 & 18 & $3.62 \times 10^{-9}$ \\
\hline & Low & 5 & 22 & 92 & \\
\hline \multirow[t]{2}{*}{ Finger movements } & High & 10 & 35 & 20 & $1.65 \times 10^{-10}$ \\
\hline & Low & 5 & 16 & 98 & \\
\hline \multirow[t]{2}{*}{ General movements } & High & 0 & 16 & 49 & 0.308 \\
\hline & Low & 4 & 19 & 96 & \\
\hline
\end{tabular}

Red: statistically highly significant ( $p$-value $<0.001$ ); Violet: statistically significant ( $p$-value $<0.05)$; Black: statistically insignificant 
which had a score of 0 for this parameter and severe oligohydramnios (amniotic fluid index score under 5). Overall, in this subgroup, we observed a reduced volume of amniotic fluid and less active fetal movements.

We compared the distribution of KANET scores in the three groups: low-risk pregnancies, threatened preterm delivery, and other high-risk depending on the classification of the results (abnormal, borderline, and normal), and we noticed highly significant differences between them. The chi-square test $p$-value was $p=0.00000106<0.001$. The analysis of variance (ANOVA) also showed significant differences between the mean values of KANET. Because the ANOVA test result was significant, we used a post hoc Tukey honest significant difference test to identify the two groups between which differences are observed. Thus, we found that the mean values of the low-risk group are higher than the other two groups. In the threatened preterm delivery group, we compared the distribution of two subgroups (with and without preterm premature rupture of membrane) and we had no significant differences (chi-square test $\mathrm{p}$-value $=0.525>0.005)$, although an abnormal or borderline KANET score is higher in the subgroup with preterm premature rupture of membrane.

The median values of movements of the fetuses in low-risk pregnancies were different from those in pregnancies threatened by premature birth and from the rest of high-risk pregnancies.

Fetuses from high-risk pregnancies, including threat of premature birth, had a less active fetal behavior than those from the low-risk group.

\section{CONCLUSION}

In recent years, it has been attempted to create a diagnostic test for the assessment of fetal behavior. The KANET is the first 4D US prenatal neurological screening test with encouraging results. ${ }^{12-15}$

Our study shows that some prenatal conditions are temporarily affecting the fetal neurological status and that the KANET might be useful for neurobehavioral assessments. The KANET appears to be able to differentiate fetuses with normal and abnormal neurological development and this gives major contribution to understanding more about functions and development of fetal central nervous system. ${ }^{5,16-19}$ Neurological disability is one of the most feared complications in perinatal medicine and its diagnosis antenatally is one of the greatest challenges in obstetrics. ${ }^{20,21}$

In Romania, the KANET is used as an evaluation test in clinical practice, but in order to introduce it as a screening tool, more research is needed in our department of materno-fetal medicine. Until now, we observed the great potential for the antenatal detection of serious neurological problems.

\section{REFERENCES}

1. Yigiter $A B, K a v a k Z N$. Normal standards of fetal behavior assessed by four-dimensional sonography. J Matern Fetal Neonatal Med 2006 Nov;19(11):707-721.

2. Rees S, Harding R. Brain development during fetal life: influences of the intra-uterine environment. Neurosci Lett 2004 May;361(1-3):111-114.

3. Joseph R. Fetal brain and cognitive development. Dev Rev 2000 Mar;20(1):81-98.

4. de Vries JI, Fong BF. Normal fetal motility: an overview. Ultrasound Obstet Gynecol 2006 Jun;27(6):701-711.

5. de Vries JI, Fong BF. Changes in fetal motility as a result of congenital disorders: an overview. Ultrasound Obstet Gynecol 2007 May;29(5):590-599.

6. Barišić LS, Stanojević M, Kurjak A, Porović S, Gaber G. Diagnosis of fetal syndromes by three- and four-dimensional ultrasound: is there any improvement? J Perinat Med 2017 Aug;45(6):651-665.

7. Kurjak A, Miskovic B, Stanojevic M, Amiel-Tison C, Ahmed B, Azumendi G, Vasilj O, Andonotopo W, Turudic T, SalihagicKadic A. New scoring system for fetal neurobehavior assessed by three- and four-dimensional sonography. J Perinat Med 2008 Feb;36(1):73-81.

8. Hata T, Kanenishi K, Akiyama M, Tanaka H, Kimura K. Realtime 3-D sonographic observation of fetal facial expression. J Obstet Gynaecol Res 2005 Aug;31(4):337-340.

9. Kozuma S, Baba K, Okai T, Taketani Y. Dynamic observation of the fetal face by three-dimensional ultrasound. Ultrasound Obstet Gynecol 1999 Apr;13(4):283-284.

10. Kurjak A, Andonotopo W, Hafner T, Salihagic Kadic A, Stanojevic M, Azumendi G, Ahmed B, Carrera JM, Troyano JM. Normal standards for fetal neurobehavioral developments: longitudinal quantication by four-dimensional sonography. J Perinat Med 2006 Feb;34(1):56-65.

11. Goldstone AP, Holland AJ, Hauffa BP, Hokken-Koelega AC, Tauber M; speakers contributors at the Second Expert Meeting of the Comprehensive Care of Patients with PWS. Recommendations for the diagnosis and management of Prader-Willi Syndrome. J Clin Endocrinol Metab 2008 Nov;93(11):4183-4197.

12. Kurjak A, Ahmed B, Abo-Yaguab S, Younis M, Saleh H, Shaddad AN, Vasilj O, Al Bahar AJ, Miskovic B, Khenyab N. An attempt to introduce neurological test for fetus based on 3D and 4D sonography. Donald School J Ultrasound Obstet Gynecol 2008 Oct-Dec;2(4):29-44.

13. Kurjak A, Abo-Yaqoub $S$, Stanojevic $M$, Yigiter AB, Vasilj $O$, Lebit D, Shaddad AN, Ahmed B, Kavak ZN, Miskovic B, et al. The potential of $4 \mathrm{D}$ sonography in the assessment of fetal neurobehavior: multicentric study in high-risk pregnancies. J Perinat Med 2010 Jan;38(1):77-82.

14. Miskovic B, Vasilj O, Stanojevic M, Ivankovic D, Kerner M, Tikvica A. The comparison of fetal behavior in high-risk and normal pregnancies assessed by four-dimensional ultrasound. J Matern Fetal Neonatal Med 2010 Dec;23(12):1461-1467.

15. Talic A, Kurjak A, Ahmed B, Stanojevic M, Predojevic M, Salihagic Kadic A, Di Renzo GC. The potential of 4D sonography in the assessment of fetal behavior in high-risk pregnancies. J Matern Fetal Neonatal Med 2011 Jul;24(7):948-954. 
16. Predojević M, Stanojević M, Vasilj O, Kadić AS. Postnatal neurological evaluation of a fetus and newborn from pregnancy complicated with IUGR and fetal hypoxemia. J Matern Fetal Neonatal Med 2011 May;24(5):764-767.

17. Athanasiadis AP, Mikos T, Tambakoudis GP, Theodoridis TD, Papastergiou M, Assimakopoulos E, Tarlatzis BC. Neurodevelopmental fetal assessment using KANET scoring system in low and high risk pregnancies. J Matern Fetal Neonatal Med 2013 Mar;26(4):363-368.

18. Abo-Yaqoub S, Kurjak A, Mohammed AB, Shadad A, AbdelMaaboud M. The role of 4-D ultrasonography in prenatal assessment of fetal neuro behaviour and prediction of neurological outcome. J Matern Fetal Neonatal Med 2012 Apr;25(3):231-236.

19. Strijbis EM, Oudman I, van Essen P, MacLennan AH. Cerebral palsy and the application of international criteria for acute intrapartum hypoxia. Obstet Gynecol 2006 Jun;107(6):1357-1365.

20. Stanojevic M, Zaputovic S, Bosnjak AP. Continuity between fetal and neonatal neurobehavior. Semin Fetal Neonat Med 2012 Dec;17(6):324-329.

21. Haak P, Lenski M, Hidecker MJ, Li M, Paneth N. Cerebral palsy and aging. Dev Med Child Neurol 2009 Oct;51(Suppl 4): 16-23. 